\title{
Kangaroo adipose tissue has higher concentrations of cis 9, trans 11-conjugated linoleic acid than lamb adipose tissue ${ }^{*}$
}

\author{
C.F. Engelke ${ }^{1,2}$, B.D. Siebert ${ }^{3}$, K. Gregg ${ }^{4}$, A-D.G. Wright ${ }^{2}$ \\ and P.E. Vercoe ${ }^{1,5}$ \\ ${ }^{1}$ Animal Biology, University of Western Australia \\ ${ }^{2}$ CSIRO Livestock Industries, Centre for Environmental and Life Sciences \\ Floreat Park, Western Australia \\ ${ }^{3}$ Department of Animal Science, University of Adelaide, South Australia \\ ${ }^{4}$ Centre for High-Throughput Agricultural Genetic Analysis, Murdoch University \\ Western Australia
}

\begin{abstract}
Ruminant tissues and products contain conjugated linoleic acids (CLA) due to biohydrogenation in the rumen. We hypothesize that kangaroos would have higher concentrations of CLA compared to lambs due to incomplete biohydrogenation of fatty acids in the kangaroo foregut. Fatty acid composition of adipose tissue (including cis 9, trans 11 CLA) from lambs and kangaroos were significantly different. The concentrations of CLA and its precursor trans vaccenic acid (TVA) in the adipose tissue of kangaroos were approximately four and five times that of lambs. Kangaroo fat was significantly less saturated and had a lower melting point.
\end{abstract}

KEY WORDS: CLA, lamb, kangaroo, fatty acids, desaturase

\section{INTRODUCTION}

Conjugated linoleic acids (CLA) represent a series of isomers derived from octadecadienoic acid found in ruminant fat as a result of biohydrogenation in the foregut. In addition the animal synthesises CLA endogenously in mammary and adipose tissue. CLA has been found to have anticarcinogenic properties in vivo and to reduce the incidence of tumours in animal models (Bauman et al., 2000). The fatty acid profiles of ruminant meats are more saturated than other species,

\footnotetext{
* Supported by the Rural Industries Research and Development Corporation.

${ }^{5}$ Corresponding author: e-mail: pvercoe@agric.uwa.edu.au
} 
such as monogastrics, due to biohydrogenation in the rumen. The kangaroo, a marsupial, is not a ruminant but does have a microbial population in its foregut that ferments forage (Moir et al., 1954), where biohydrogenation occurs. However, fats in the kangaroo are relatively high in unsaturated fatty acids and low in saturated fatty acids. Ford and Fogerty (1982) measured total conjugated 18:2 dienes in kangaroo meat and reported levels similar to those found in ruminants. The degree of saturation may be affected by other factors. For example, the rate of digesta flow in the kangaroo is generally faster in the digestive tract than that of sheep (Forbes and Tribe, 1970) and the pattern of digesta flow is different between these two species (Dellow, 1982).

Previously, we examined the fatty acid composition of digesta from lambs and kangaroos grazing in the same area (Engelke et al., 2004). It appears that biohydrogenation in the kangaroo foregut is not as extensive as in the rumen of the lamb because there was less saturated fatty acid in the kangaroo digesta. CLA concentrations in the digesta from the gastric stomach of kangaroos and lambs were not significantly different. However trans vaccenic acid (TVA) concentration in kangaroo digesta was significantly higher than that of lambs. This may result in a higher concentration of cis 9, trans 11 CLA due to a greater supply of TVA for endogenous synthesis. We hypothesise that cis 9, trans 11 CLA concentrations in adipose tissue will be higher in kangaroos than in lambs.

\section{MATERIAL AND METHODS}

Subcutaneous adipose tissue overlying the M. longissimus dorsi, was sampled from lambs (Dorset X Merino; 7 months of age; $\mathrm{n}=10$ ) and Western Grey kangaroos (Macropus fuliginosus; $\mathrm{n}=10$ ) grazing in the same area at Badgingarra, Western Australia. Samples were frozen in dry ice and stored at $-20^{\circ} \mathrm{C}$ until analysis. Fatty acid composition of adipose lipid was determined by gas liquid chromatography. Samples $(100 \mathrm{mg})$ were prepared for analysis by alkaline methylation procedures (Christie, 1989). Separation of individual fatty acids was carried out by GLC using a BPX70 capillary column (SGE, Melbourne, Australia). The system allowed the identification of cis/trans isomers. Methyl esters were identified by comparisons to fatty acid standards. The slip point method was used to measure the melting point of the adipose tissue (AOC, 1993). Statistical analyses were performed by analysis of variance (Genstat $6^{\text {th }}$ Edition).

\section{RESULTS}

The concentration of cis 9, trans 11 CLA was significantly higher in the kangaroo than the lamb ( 3.8 vs $1.0 \% ; \mathrm{P}<0.001$; Table 1 ). The TVA concentrations were also significantly higher in the kangaroo adipose tissue (12.4 vs $2.6 \%$; 
$\mathrm{P}<0.001$; Table 1). The melting point of kangaroo adipose was significantly less than that of lamb adipose (Table 1). This is reflected in the higher concentrations of monounsaturated and polyunsaturated fatty acids in kangaroo adipose tissue in lamb adipose tissue.

Table 1. Melting point and the concentration of major fatty acids of adipose tissue sampled from kangaroos and lambs in the same area, $\mathrm{g} / 100 \mathrm{~g}$

\begin{tabular}{lrrrrr}
\hline & \multicolumn{2}{c}{ Kangaroo, $\mathrm{g} / 100 \mathrm{~g}$} & & \multicolumn{2}{c}{ Lamb, $\mathrm{g} / 100 \mathrm{~g}$} \\
\cline { 2 - 3 } \cline { 5 - 6 } \cline { 5 - 6 } Melting point, ${ }^{\circ} \mathrm{C}$ & mean & $\mathrm{Se}$ & & mean & Se \\
\cline { 5 - 6 } \% of total fatty acids & 36.1 & 1.03 & & 44.0 & 0.43 \\
$14: 0^{\mathrm{a}}$ & & & & & \\
$14: 1^{\mathrm{a}}$ & 2.4 & 0.10 & & 9.4 & 0.53 \\
$16: 0^{\mathrm{a}}$ & 0.8 & 0.06 & & 0.2 & 0.03 \\
$16: 1(11) \mathrm{c}^{\mathrm{b}}$ & 18.1 & 0.39 & & 27.7 & 0.53 \\
$18: 0^{\mathrm{a}}$ & 2.7 & 0.49 & & 0.9 & 0.19 \\
$18: 1(11)^{1, \mathrm{a}}$ & 12.7 & 1.21 & & 19.4 & 0.63 \\
$18: 1(9) \mathrm{c}$ & 12.4 & 0.96 & & 2.6 & 0.19 \\
$18: 2(6) \mathrm{c}^{\mathrm{a}}$ & 31.5 & 1.10 & & 27.9 & 0.74 \\
$18: 2(9) \mathrm{c},(11) \mathrm{t}^{2, \mathrm{a}}$ & 4.4 & 0.20 & & 2.5 & 0.09 \\
$18: 3(3)^{\mathrm{a}}$ & 3.8 & 0.30 & & 1.0 & 0.06 \\
\hline
\end{tabular}

${ }^{1}$ TVA. ${ }^{2}$ CLA; ${ }^{\text {ab }}$ reflect significant differences: ${ }^{\text {a }} \mathrm{P}<0.001,{ }^{\text {b }} \mathrm{P}<0.005$

\section{DISCUSSION}

As hypothesised, the cis 9, trans 11 CLA concentration in kangaroo adipose was higher than that in lamb adipose. The concentration in adipose tissue from kangaroos was almost four times that of lamb $(\mathrm{P}<0.001)$. More saturated fatty acid (14:0, 16:0 and 18:0) and less monounsaturated fatty acid (14:1, 16:1(11)c and 18:1(9)c) in lamb adipose tissue confirm our previous findings that greater biohydrogenation of fatty acids occurs in the rumen than in the foregut of the kangaroo. The difference in biohydrogenation may be due to the faster passage of digesta through the kangaroo digestive tract or differences in the microorganisms present in the foregut and rumen. It is most likely that it is due to a combination of both these factors because the differences between species are not consistent for each fatty acid.

The CLA concentration in kangaroos was higher in the adipose tissue than in the digesta therefore it is likely that the majority of the CLA in the adipose tissue was formed via endogenous synthesis. The concentrations of CLA were not significantly different in the digesta from the two species (Engelke et al., 2004) but they were in the adipose tissues. 
Under the sampling conditions of this experiment, kangaroos had higher levels of CLA than lambs and higher than previously reported levels from ruminant animals. The lambs and kangaroos used in this study were from the same paddock at Badgingarra, Western Australia. However there were no fences to prevent kangaroos from leaving the paddock and feeding elsewhere. In addition to this, kangaroos and lambs may select forage differently. A more controlled experiment, where the two species are fed the same diet, would be able to define the difference between kangaroos and lambs more precisely. Despite the limitations of this experiment, we have demonstrated that kangaroos do indeed produce high concentrations of cis 9, trans 11 CLA and at levels higher than previously reported from other species.

\section{CONCLUSIONS}

Adipose tissue of kangaroos has a higher cis 9, trans 11 CLA concentration than adipose tissue of lambs. Kangaroo adipose tissue is less saturated and more unsaturated than that of lambs, probably due to absorption of fatty acids that are not fully hydrogenated in the foregut of kangaroos.

Previously, we have reported that there is less extensive biohydrogenation of fatty acids, similar levels of CLA and much higher levels of TVA in the kangaroo foregut than in the rumen. Therefore the majority of the cis 9, trans 11 CLA in kangaroo adipose tissue is most likely to come from endogenous synthesis of this isomer from TVA.

\section{REFERENCES}

AOCS, 1993. Official Methods. American Oil Chemists' Society, Champaign, Illinois, pp. 3-25

Bauman D.E., Baumgard L.H., Corl B.A., Griinari J.M., 1999. Biosynthesis of conjugated linoleic acid in ruminants. Proc. Amer. Soc. Anim. Sci. 1-15

Christie W.W., 1989. Gas Chromatography and Lipids. The Oily Press, Ayr (Scotland)

Dellow D.W., 1982. Studies on the nutrition of macropodine marsupials III. The flow of digesta through the stomach and intestine of macropodines and sheep. Aust. J. Zool. 30, 751-65

Engelke C.F., Siebert B.D., Gregg K., Wright A-D. G., Vercoe P.E., 2004. Kangaroos have unusually high concentrations of TVA in their foregut. Proceedings of the Gut Microbiology Conference, Clermont-Ferrand Theix (France) (in press)

Forbes D.K., Tribe D.E., 1970. The utilisation of roughages by sheep and kangaroos. Aust. J. Zool. $18,247-56$

Ford G.L., Fogerty A.C., 1982. The fatty acids of kangaroo and wallaby meat. CSIRO Food Res. Quart. 42, 60-4

Moir R.J., Somers M., Sharman G., Waring H., 1956. Studies on marsupial nutrition. 1. Ruminantlike digestion in a herbivorous marsupial. Aust. J. Biol Sci. 9, 293-304 